\title{
Glucose Intolerance after a Recent History of Gestational Diabetes
}

\author{
Katrien Benhalima, ${ }^{1}$ Liesbeth Leuridan, ${ }^{1}$ Peggy Calewaert, ${ }^{1}$ \\ Roland Devlieger, ${ }^{2}$ Johan Verhaeghe, ${ }^{2}$ and Chantal Mathieu ${ }^{1}$ \\ ${ }^{1}$ Department of Endocrinology, UZ Gasthuisberg, KU Leuven, Herestraat 49, 3000 Leuven, Belgium \\ ${ }^{2}$ Department of Obstetrics \& Gynecology, UZ Gasthuisberg, KU Leuven, Herestraat 49, 3000 Leuven, Belgium
}

Correspondence should be addressed to Katrien Benhalima; katrien.benhalima@uzleuven.be

Received 10 June 2014; Revised 17 July 2014; Accepted 23 July 2014; Published 7 August 2014

Academic Editor: Hyun C. Lee

\begin{abstract}
Copyright (C) 2014 Katrien Benhalima et al. This is an open access article distributed under the Creative Commons Attribution License, which permits unrestricted use, distribution, and reproduction in any medium, provided the original work is properly cited.
\end{abstract}

\begin{abstract}
Aim. Our aim was to evaluate the uptake of our current screening strategy postpartum and the risk factors for glucose intolerance in women with a recent history of gestational diabetes (GDM). Methods. Retrospective analysis of files of women with a recent history of GDM diagnosed with the Carpenter and Coustan criteria from 01-01-2010 till 31-12-2013. Multivariable logistic regression was used to adjust for confounders. Results. Of all 231 women with a recent history of GDM, 21.4\% (46) did not attend the scheduled postpartum OGTT. Of the women tested, 39.1\% (66) had glucose intolerance and 5.3\% (9) had diabetes. These women were more often overweight $(39.7 \%$ versus $25.3 \%, P=0.009)$, were more often treated with basal-bolus insulin injections $(52.0 \%$ versus $17.4 \%$, $P=0.032$ ), and had a lower beta-cell function and lower insulin sensitivity, remaining significant after adjustment for age, BMI, and ethnicity (insulin secretion sensitivity index-2 (ISSI-2) in pregnancy $1.5 \pm 0.5$ versus $1.7 \pm 0.4, P=0.029$; ISSI-2 postpartum $1.5(1.2-1.9)$ versus $2.2(1.8-2.6), P=0.020$; Matsuda index postpartum 3.8 (2.6-6.2) versus $6.0(4.3-8.8), P=0.021)$. Conclusion. Glucose intolerance is frequent in early postpartum and these women have a lower beta-cell function and lower insulin sensitivity. One fifth of women did not attend the scheduled OGTT postpartum.
\end{abstract}

\section{Introduction}

Gestational diabetes (GDM) is a frequent medical condition during pregnancy and was historically defined as "any degree of glucose intolerance with onset or first recognition during pregnancy" [1]. Internationally, the best approach for screening and diagnosis of GDM remains controversial. The "International Association of Diabetes and Pregnancy Study Groups" (IADPSG) recommends a one-step screening strategy with the 2-hour $75 \mathrm{~g}$ oral glucose tolerance test (OGTT) using stricter criteria to diagnose GDM [2]. The latest 2014 American Diabetes Association (ADA) recommendations leave open the option between the one-step IADPSG recommendation and the two-step screening strategy with a glucose challenge test (GCT) [3]. Using the IADPSG criteria on the "Hyperglycemia and Adverse Pregnancy Outcomes" (HAPO) cohort, GDM prevalence varied from $9.3 \%$ to $>25 \%$ depending on the populations studied [4].
GDM is associated with an increased risk for a large for gestational age (LGA) baby, which in turn increases risks of shoulder dystocia and caesarian deliveries [5]. When the baby is female, exposure to maternal hyperglycaemia in utero might increase her own risk of subsequently developing GDM in her own pregnancies [6]. Shortly after delivery, the glucose values are generally restored to normal, but women with GDM have a sevenfold increased risk of developing T2DM [7]. The risk of women with GDM, diagnosed with the Carpenter and Coustan criteria, to develop T2DM postpartum depends on the populations studied and is generally around $30-50 \%$ within 10 years after the index pregnancy [7]. The best postpartum screening strategy for glucose intolerance among women with a history of GDM is still debated. The ADA now recommends to screen women with a history of GDM at 6-12-week postpartum using the $2 \mathrm{~h} 75 \mathrm{~g}$ oral glucose tolerance test (OGTT) and nonpregnancy diagnostic 
criteria but this is mostly based on expert consensus or clinical experience [3]. The ADA further advises that these women have lifelong screening for the development of T2DM and prediabetes at least every 3 years, by using Hbalc, FPG, or the $2 \mathrm{~h} 75 \mathrm{~g}$ OGTT [3]. In routine clinical care, postpartum testing in women with a previous history of GDM rates often remains around $50 \%$ [8].

More data are necessary in different populations on the risk factors, both clinical and biochemical, to develop glucose intolerance in early postpartum. The aim of our study was to evaluate the uptake of our current screening strategy postpartum and to determine the prevalence and the risk factors for early postpartum glucose intolerance in women with a recent history of GDM.

\section{Subjects and Methods}

Retrospective analysis of the electronic medical files of the University Hospital UZ Leuven in Belgium, from 01-01-2010 till 31-12-2013 of all women with a recent history of GDM diagnosed with the Carpenter and Coustan criteria. The study was approved by the Institutional Review Board of UZ Leuven (ML 10085).

Approximately 2400 women are delivered annually at our hospital. The background prevalence of T2DM in Belgium is $5.3 \%$ [9]. In the general adult population, $28 \%$ of women are overweight and $13 \%$ are obese [10]. Leuven is a medium size city in the region of Flanders and has a population with a rather low background number of women from ethnic minorities (BME) (10.9\%) [10]. Accurate data on the prevalence of GDM are lacking in Belgium and the current practice for screening for GDM varies across different centers [11]. The lack of consensus on screening for GDM is also apparent in the two linguistic regions of Belgium: a recent Flemish consensus between endocrinologists, gynecologists, and general physicians advises at this moment to continue with the two-step screening strategy while the recent consensus of the French-speaking obstetricians is to adopt the IADPSG strategy for GDM $[12,13]$.

Women are not yet universally screened for overt diabetes early in pregnancy in our hospital. All pregnant women were screened and diagnosed for GDM according to the Fifth International Workshop Conference criteria [14]. Women received a GCT and those testing positive (threshold after $1 \mathrm{~h} \geq 140 \mathrm{mg} / \mathrm{dL}(7.8 \mathrm{mmol} / \mathrm{L})$ ) had a $3 \mathrm{~h} 100 \mathrm{~g}$ OGTT at 24-28 gestational weeks using the Carpenter and Coustan criteria for GDM (FPG $\geq 95 \mathrm{mg} / \mathrm{dL}(5.3 \mathrm{mmol} / \mathrm{L})$, $1 \mathrm{~h}$ glycaemia $\geq 180 \mathrm{mg} / \mathrm{dL}(10.0 \mathrm{mmol} / \mathrm{L}), 2 \mathrm{~h}$ glycaemia $\geq$ $155 \mathrm{mg} / \mathrm{dL}(8.6 \mathrm{mmol} / \mathrm{L})$, and $3 \mathrm{~h}$ glycaemia $\geq 140 \mathrm{mg} / \mathrm{dL}$ (7.8 mmol/L), diagnosis of GDM if $\geq 2$ values are abnormal). Previous research from our group showed that the GDM prevalence in our hospital is $3.3 \%$ using the Carpenter and Coustan criteria $[15,16]$. Women with GDM were treated with insulin 1-2 weeks after the implementation of dietary measures when FPG $\geq 95 \mathrm{mg} / \mathrm{dL}(5.3 \mathrm{mmol} / \mathrm{L})$ and/or $2 \mathrm{~h}$ postprandial glycaemia $\geq 120 \mathrm{mg} / \mathrm{dL}(6.7 \mathrm{mmol} / \mathrm{L})$. In our center, oral antidiabetes drugs are not routinely used during pregnancy. In UZ Leuven, since January 2010, every woman with a previous diagnosis of GDM is advised to receive a $2 \mathrm{~h} 75 \mathrm{~g}$ OGTT 3 months after the delivery. Before 2010, only insulin-treated women with GDM received an $75 \mathrm{~g}$ OGTT postpartum in our center. There are no data in our database on how long or how exclusive breastfeeding was given. There are no general recommendations on breastfeeding and OGTT postpartum in Belgium but the general recommendation in our hospital is to postpone the OGTT to 6-month postpartum if women are still breastfeeding at 3 months. If women are still breastfeeding at 6 months, the OGTT is performed despite the breastfeeding.

Outcomes were obtained from review of the electronic database. Maternal characteristics recorded were age, weight, body mass index (BMI) at first prenatal visit and at delivery, overweight $\left(\mathrm{BMI} \geq 25 \mathrm{Kg} / \mathrm{m}^{2}\right)$, obesity $\left(\mathrm{BMI} \geq 30 \mathrm{Kg} / \mathrm{m}^{2}\right)$, weight gain (difference in weight between first prenatal visit and the delivery), ethnicity, parity, smoking and alcohol habits, family history of diabetes, history of GDM, history of polycystic ovary syndrome (PCOS), hypertension, dyslipidemia, and glucose intolerance before pregnancy. Excessive weight gain was defined according to the most recent Institute of Medicine (IOM) guidelines, except for obese women for whom we use the recommendation to gain $\leq 5 \mathrm{Kg}$ during pregnancy [17]. Other data that were recorded are whether or not the scheduled postpartum OGTT was attended, the timing of the OGTT postpartum, the glucose values and the insulin values based on the $75 \mathrm{~g}$ OGTT postpartum ( 0 min-30 min-60 min-120 min) and based on the $100 \mathrm{~g}$ OGTT during pregnancy (0 min-60 min-120 min-180 min), whether women breastfed or not, type of contraception used postpartum, gestational age at delivery, the timing and result of the GCT, the gestational age at the diagnosis of GDM, $\mathrm{HbAlc}$ at the time of the $100 \mathrm{~g}$ OGTT during pregnancy, whether women received treatment with corticoids during pregnancy after the screening test, need of insulin, type of insulin and number of injections, and the gestational age at the start of insulin.

Maternal outcomes recorded were diabetes postpartum (FPG $\geq 126 \mathrm{mg} / \mathrm{dL}(7.0 \mathrm{mmol} / \mathrm{L})$ and/or 2 hour glycaemia at the OGTT postpartum $\geq 200 \mathrm{mg} / \mathrm{dL}(11.1 \mathrm{mmol} / \mathrm{L}))$ and glucose intolerance postpartum (impaired fasting glucose with a FPG $\geq 100-125 \mathrm{mg} / \mathrm{dL}(5.5-6.9 \mathrm{mmol} / \mathrm{L})$ and/or impaired glucose tolerance with a 2-hour glycaemia at the OGTT postpartum $\geq 140-199 \mathrm{mg} / \mathrm{dL}(7.8-11.0 \mathrm{mmol} / \mathrm{L}))$ [3].

Insulin sensitivity was measured using the insulin sensitivity index of Matsuda, a well-established measure of wholebody insulin sensitivity [18]. The insulin sensitivity index of Matsuda is defined as $10000 / \sqrt{ }((F P G \times$ fasting plasma insulin $) \times($ mean glucose during OGTT $\times$ mean insulin during OGTT)) [18]. As a secondary measure of insulin sensitivity (largely hepatic), we also calculated the reciprocal of the homeostasis model assessment of insulin resistance (1/HOMA-IR) [19]. HOMA-IR is calculated as the product of FPG and fasting plasma insulin divided by 22.5 [19]. Beta-cell function was assessed by the insulinogenic index dived by HOMA-IR. The insulinogenic index was calculated as the incremental change in insulin concentration during the first $30 \mathrm{~min}$ of the OGTT divided by the incremental 
change in glucose during the same period [20, 21]. As a secondary measure of beta-cell function, the insulin secretion sensitivity index (ISSI-2) was measured, an OGTT-derived measure that is analogous to the disposition index obtained from the frequently sampled intravenous glucose tolerance test $[22,23]$. Glycaemia was assessed by the area under the glucose curve during the OGTT, calculated using the trapezoidal rule $[22,23]$. ISSI-2 is defined as the product of (1) insulin secretion measured by the ratio of the area under the insulin curve to the area under the glucose curve and (2) insulin sensitivity measured by the insulin sensitivity index of Matsuda [22, 23]. All these measures have been validated for use in pregnancy.

$\mathrm{HbA}_{1 \mathrm{c}}$ was measured by reversed-phase cation-exchange chromatography (ADAMS HA-8160, Menarini Diagnostics Benelux, Zaventem, Belgium). Plasma glucose was measured by an automated colorimetric-enzymatic method (hexokinase-glucose-6-phosphate-dehydrogenase, application 668) on a Hitachi/Roche-Modular P analyzer. Insulin was measured by the immunometric ECLIA (Roche Modular E170, Basel, Switzerland).

Statistical Analyses. Statistical analyses were performed using SPSS 22.0. Continuous data were expressed as mean and standard deviation if normally distributed; nonparametric variables were expressed as median. Categorical data were expressed as percentage. To compare variables between two groups, independent samples $t$-tests were used for normally distributed continuous variables, Mann-Whitney $U$ test for nonparametric variables, and chi-squared tests for categorical variables. Multivariable logistic regression was used to analyse the impact of possible confounders such as age, BMI, ethnicity, breastfeeding, contraception, multiparity, and corticoid treatment on insulin sensitivity and beta-cell function. A $P$ value of $<0.05$ (two-tailed) was considered significant.

\section{Results}

Over a 4-year period, 255 women were identified with a recent history of GDM. After evaluation of the medical files, 24 files were not included in the analysis due to insufficient data (9), because women only had one abnormal value on the OGTT (9) or because women took part in a study using the IADPSG criteria for GDM (6), leaving a cohort of 231 women with a recent history of GDM for analysis. Of all the 231 women, 16 women did not receive an appointment in our hospital for the postpartum OGTT due to the diagnosis of T2DM (6) or MODY-2 (1) early after the delivery or because the postpartum OGTT was planned in another local hospital (9).

The mean age of the cohort was 32.3 years $( \pm 4.8), 12.6 \%$ (29) had a previous history of GDM, 36.4\% (84) had a BME background, $34.2 \%$ (75) were overweight, and 23.3\% (51) were obese at the first prenatal visit. The most frequent BME background was Northern-African (10.0\%), Black African (7.8\%), South Asian (11.3\%), and Middle East (4.3\%). The median week at diagnosis of GDM was 27.0 (25.0-29.0) and
$29.6 \%$ (68) of women needed insulin during pregnancy. Of all women, $71.4 \%$ (165) were breastfeeding.

Of all women (215) who received an appointment for a postpartum OGTT, $21.4 \%$ (46) did not attend the scheduled OGTT. Moreover, $10.7 \%$ (20) of all OGTT's postpartum were only performed after a telephonic recall for a new appointment after missing the first scheduled OGTT. Compared to women who received an OGTT postpartum, women who did not attend the postpartum OGTT had more often a previous history of smoking before pregnancy $(10.9 \%$ versus $2.4 \%, P=$ $0.021)$, had more often a previous history of GDM $(21.7 \%$ versus $10.7 \%, P=0.042)$, were less often breastfeeding $(56.5 \%$ versus $75.7 \%, P=0.011$ ), and had a significant lower insulin sensitivity based on the OGTT during pregnancy (Table 1). The postpartum OGTT was performed at a median of 12 weeks (8-13) with a minimum of 6 weeks. The OGTT was performed at the latest at six months postpartum expect for one woman at 32 weeks.

Of all women (169) receiving an OGTT postpartum, $39.1 \%$ (66) had glucose intolerance of which $21.2 \%(14 / 66)$ had impaired fasting glucose (IFG), 66.7\% (44/66) had impaired glucose tolerance (IFG), and 12.1\% (8/66) had IFT/IGT combined. Of all women (169) receiving an OGTT postpartum, $5.3 \%$ (9) had diabetes: one women had diabetes based on the FPG $(173 \mathrm{mg} / \mathrm{dL}(9.6 \mathrm{mmol} / \mathrm{L}))$ and 8 women had diabetes based on the 2-hour glycaemia on the OGTT (values ranging from 206 to $288 \mathrm{mg} / \mathrm{dL}(11.4-16.0 \mathrm{mmol} / \mathrm{L}))$. Compared to women with a normal OGTT postpartum, women with glucose intolerance (IFG and/or IGT) or diabetes were more often overweight (39.7\% versus $25.3 \%, P=0.009$ ) or obese at first prenatal visit $(27.4 \%$ versus $19.5 \%, P=0.037)$, were more often multiparous ( $44.0 \%$ versus $26.6 \%, P=0.028)$, had a higher glucose value after the GCT $(168.0 \mathrm{mg} / \mathrm{dL}$ (153.0190.0 ) versus $159.0 \mathrm{mg} / \mathrm{dL}(149.5-175.5), P=0.007)$, had an earlier diagnosis of GDM (gestational weeks 26.0 (25.028.0) versus $27.0(25.0-29.0), P=0.030)$, had a higher median fasting $(94.5 \mathrm{mg} / \mathrm{dL}(84.2-101.7)$ versus $88.0 \mathrm{mg} / \mathrm{dL}$ (81.0-99.0), $P=0.006$ ) and 2-hour glucose value on the OGTT during pregnancy $(175.0 \mathrm{mg} / \mathrm{dL}(162.0-198.0)$ versus $168.0 \mathrm{mg} / \mathrm{dL}(158.0-181.0), P=0.003)$, and were more often treated with basal-bolus insulin injections (52.0\% versus $17.4 \%, P=0.032$ ) (Table 2). Women with glucose intolerance or diabetes postpartum also had a significant impaired betacell function and lower insulin sensitivity, remaining significant after adjustment for age, BMI, ethnicity, breastfeeding, contraception, multiparity, and corticoid treatment (Table 3). The data also remained significantly different when the 9 women with diabetes were not included in the analysis.

Compared to women with IGT based on the 2-hour glucose value postpartum, women with IFG postpartum were more often obese ( $50 \%$ versus $14.3 \%, P=0.006)$, had an earlier diagnosis of GDM (gestational weeks 25.0 (20.527.0) versus $27.0(25.0-28.7), P=0.029)$, had a higher median fasting $(99.5 \mathrm{mg} / \mathrm{dL}(96.2-121.0)$ versus $89.0 \mathrm{mg} / \mathrm{dL}$ (84.0-101.0), $P=0.022$ ) and 1-hour glucose value on the OGTT during pregnancy (202.5 mg/dL (183.0-226.2) versus $189.0 \mathrm{mg} / \mathrm{dL}$ (170.0-202.0), $P=0.047)$, had more often four abnormal glucose values on the OGTT during pregnancy (41.7\% versus $14.0 \%, P=0.034)$, and insulin was started 
TABLE 1: Comparison of the characteristics between women who received an OGTT postpartum and women who failed to attend the scheduled OGTT postpartum.

\begin{tabular}{|c|c|c|c|}
\hline & $\begin{array}{c}\text { Women with OGTT } \\
\text { postpartum } \\
N=169(78.6 \%)\end{array}$ & $\begin{array}{l}\text { Women without } \\
\text { OGTT postpartum } \\
N=46(21.4 \%)\end{array}$ & $P$ value \\
\hline Age mean years & $32.2 \pm 4.7$ & $31.5 \pm 4.9$ & 0.349 \\
\hline$\%$ overweight at first prenatal visit & 31.9 & 40.9 & 0.195 \\
\hline$\%$ obese at first prenatal visit & 23.1 & 25.0 & 0.795 \\
\hline$\% \mathrm{BME}$ & 33.7 & 37.0 & 0.683 \\
\hline$\%$ smoking before pregnancy & 2.4 & 10.9 & 0.021 \\
\hline$\%$ first degree family member with T2DM & 15.4 & 13.0 & 0.580 \\
\hline$\%$ history of GDM & 10.7 & 21.7 & 0.042 \\
\hline$\%$ multiparous & 34.3 & 34.8 & 0.872 \\
\hline$\%$ breastfeeding & 75.7 & 56.5 & 0.011 \\
\hline Week OGTT (median) & $27.0(25.0-28.2)$ & $27.0(25.0-29.0)$ & 0.520 \\
\hline$\%$ fasting abnormal & 42.3 & 45.0 & 0.759 \\
\hline$\% \geq 4$ values abnormal on the $100 \mathrm{~g}$ OGTT & 13.5 & 17.9 & 0.475 \\
\hline$\%$ insulin & 28.6 & 26.1 & 0.818 \\
\hline Weeks start insulin (median) & $29.5(27.0-32.0)$ & $30.0(27.0-33.0)$ & 0.582 \\
\hline$\%$ bolus-basal injections & 35.4 & 33.3 & 0.786 \\
\hline pISSI-2 mean & $1.6 \pm 0.4$ & $1.6 \pm 0.6$ & 0.690 \\
\hline pMatsuda (median) & $2.8(1.9-3.8)$ & $2.2(1.5-3.1)$ & 0.033 \\
\hline p1/HOMA-IR (median) & $0.020(0.012-0.032)$ & $0.015(0.010-0.023)$ & 0.030 \\
\hline
\end{tabular}

BME: ethnic minority backgrounds; T2DM: type 2 diabetes; GDM: gestational diabetes; OGTT: oral glucose tolerance test; pISSI-2: insulin secretion sensitivity index during pregnancy; pMatsuda: insulin sensitivity index of Matsuda during pregnancy; pl/HOMA-IR: the reciprocal of the homeostasis model assessment of insulin resistance during pregnancy.

earlier during pregnancy (gestational weeks 24.0 (20.7-28.2) versus 30.0 (27.5-32.0), $P=0.017)$ ) (Table 4). Women (8) with the combination of IFG and IGT were excluded from these analyses. Compared to women with IGT postpartum, women with IFG also had an impaired beta-cell function and lower insulin sensitivity based on the OGTT postpartum (Table 5). However, after adjustment for the BMI at first prenatal visit, only $1 /$ HOMA-IR remained significant $(P=$ $0.016)$.

\section{Discussion}

Our study shows that glucose intolerance is very frequent in women with a recent history of GDM. In our study, $44.4 \%$ of all women had glucose intolerance or diabetes in early postpartum. Of all women, 39.1\% had glucose intolerance of which $66.7 \%$ had IGT, $21.2 \%$ had IFG, and $12.1 \%$ had IFG and IGT combined. A FPG alone postpartum would therefore have missed the majority of women with glucose intolerance, confirming the need for an OGTT in early postpartum in our population. Studies evaluating the use of HbAlc alone or in combination with FPG to diagnose glucose intolerance in women who have had GDM show conflicting results with sensitivity rates of $\mathrm{HbAlc}$ and FPG combined ranging from $83.0 \%$ to $90.0 \%[24,25]$. We have no data on HbAlc postpartum in our cohort. The high prevalence of glucose intolerance postpartum in our cohort is probably related to the use of the Carpenter and Coustan criteria for GDM identifying women at high risk for the development of diabetes. The use of the IADPSG criteria for GDM will result in a greater proportion of women diagnosed with GDM but this will presumably lead to a lower proportion at risk for postpartum glucose intolerance [26].

The most important risk factors to develop glucose intolerance postpartum differ according to the populations studied. A recent study showed that a metabolic-syndromelike cluster in pregnant GDM women is an important predictor of the 10-year risk for T2DM [27]. In a Korean population, independent risk factors for the risk to develop T2DM in early postpartum were a higher prepregnancy BMI, higher area under the curve of glucose during an antepartum OGTT, lower fasting insulin concentration, and a decreased beta-cell function [28]. The most important risk factors in our population to develop glucose intolerance or diabetes postpartum were a higher BMI at first prenatal visit, higher glucose values on the GCT and OGTT during pregnancy, an earlier diagnosis of GDM, and the need for bolus-basal insulin injections. Breastfeeding has been associated with lower FPG and insulin, and a lower prevalence of glucose intolerance 6-9-week postpartum [29, 30]. Breastfeeding was very prevalent in our cohort of women who received an OGTT postpartum and rates were not lower in women with glucose intolerance postpartum. Maternal age at diagnosis is often considered a significant risk factor for glucose intolerance in the future but this was not a risk factor in our 
TABLE 2: Comparison of the characteristics between women with a normal OGTT and women with glucose intolerance/diabetes postpartum.

\begin{tabular}{|c|c|c|c|}
\hline & $\begin{array}{c}\text { Normal } \\
N=94(55.6 \%)\end{array}$ & $\begin{array}{c}\text { Glucose } \\
\text { intolerance/diabetes } \\
N=75(44.4 \%)\end{array}$ & $P$ value \\
\hline Age mean years & $31.8 \pm 4.8$ & $32.9 \pm 4.6$ & 0.141 \\
\hline $\mathrm{BMI} \mathrm{kg} / \mathrm{m}^{2}$ at first prenatal visit (median) & $24.1(21.5-28.9)$ & $27.8(22.9-30.7)$ & 0.019 \\
\hline$\%$ overweight at first prenatal visit & 25.3 & 39.7 & 0.009 \\
\hline$\%$ obese at first prenatal visit & 19.5 & 27.4 & 0.037 \\
\hline$\%$ excessive weight gain & 31.3 & 23.0 & 0.241 \\
\hline$\% \mathrm{BME}$ & 24.5 & 45.3 & 0.004 \\
\hline$\%$ smoking before pregnancy & 3.2 & 1.3 & 0.713 \\
\hline$\%$ first degree family member with T2DM & 16.0 & 14.7 & 0.095 \\
\hline$\%$ history of GDM & 5.3 & 17.3 & 0.016 \\
\hline$\%$ history of PCOS & 2.1 & 2.7 & 0.905 \\
\hline$\%$ history of hypertension & 3.2 & 5.3 & 0.569 \\
\hline$\%$ history of dyslipidaemia & 3.2 & 1.3 & 0.261 \\
\hline$\%$ multipareous & 26.6 & 44.0 & 0.028 \\
\hline$\%$ breastfeeding & 77.7 & 73.0 & 0.536 \\
\hline$\%$ progestin-only oral contraceptive & 62.5 & 67.8 & 0.527 \\
\hline Result GCT mg/dL (median) & $159.0(149.5-175.5)$ & $168.0(153.0-190.0)$ & 0.007 \\
\hline Week at diagnosis of GDM (median) & $27.0(25.0-29.0)$ & $26.0(25.0-28.0)$ & 0.030 \\
\hline$\% \geq 4$ values abnormal on $100 \mathrm{~g}$ OGTT & 9.1 & 19.1 & 0.069 \\
\hline Median fasting $100 \mathrm{~g}$ OGTT mg/dL & $88.0(81.0-99.0)$ & $94.5(84.2-101.7)$ & 0.006 \\
\hline Median 1 h 100 g OGTT mg/dL & $188.0(167.0-199.0)$ & $191.5(170.2-205.5)$ & 0.312 \\
\hline Median 2 h 100 g OGTT mg/dL & $168.0(158.0-181.0)$ & $175.0(162.0-198.0)$ & 0.003 \\
\hline Median 3 h 100 g OGTT mg/dL & $144.0(122.0-159.0)$ & $151.5(128.5-166.0)$ & 0.058 \\
\hline HbAlc \% (median) & $5.3(5.1-5.5)$ & $5.4(5.2-5.7)$ & 0.443 \\
\hline$\%$ corticoid treatment & 5.3 & 9.3 & 0.590 \\
\hline$\%$ insulin & 24.5 & 33.8 & 0.203 \\
\hline Weeks start insulin (median) & $30.0(28.0-32.0)$ & $29.0(26.0-32.0)$ & 0.367 \\
\hline$\%$ bolus-basal injections & 17.4 & 52.0 & 0.032 \\
\hline
\end{tabular}

BME: ethnic minority backgrounds; T2DM: type 2 diabetes; GDM: gestational diabetes; GCT: glucose challenge test: OGTT: oral glucose tolerance test; PCOS: polycystic ovary syndrome.

TABLE 3: Comparison of the beta-cell function and insulin sensitivity between women with a normal OGTT and women with glucose intolerance/diabetes postpartum.

\begin{tabular}{|c|c|c|c|c|}
\hline & $\begin{array}{l}\text { Normal } \\
N=86\end{array}$ & $\begin{array}{c}\text { Glucose } \\
\text { intolerance/diabetes } \\
N=68\end{array}$ & $P$ value & $\begin{array}{c}\text { Adjusted } \\
P \text { value }\end{array}$ \\
\hline pISSI-2 mean & $1.7 \pm 0.4$ & $1.5 \pm 0.5$ & 0.002 & 0.029 \\
\hline pMatsuda (median) & $2.9(2.0-4.1)$ & $2.7(1.7-3.7)$ & 0.273 & 0.355 \\
\hline p1/HOMA-IR (median) & $0.02(0.01-0.03)$ & $0.02(0.01-0.03)$ & 0.204 & 0.641 \\
\hline dISSI-2 (median) & $2.2(1.8-2.6)$ & $1.5(1.2-1.9)$ & $<0.0001$ & 0.020 \\
\hline dInsulinogenic index/HOMA-IR (median) & $0.013(0.010-0.019)$ & $0.008(0.005-0.014)$ & $<0.0001$ & 0.479 \\
\hline dMatsuda (median) & $6.0(4.3-8.8)$ & $3.8(2.6-6.2)$ & $<0.0001$ & 0.021 \\
\hline d1/HOMA-IR (median) & $0.036(0.027-0.056)$ & $0.026(0.018-0.052)$ & 0.013 & 0.901 \\
\hline
\end{tabular}

Only women with complete data on glucose and insulin levels were included in the analysis. pISSI-2: insulin secretion sensitivity index during pregnancy; pMatsuda: insulin sensitivity index of Matsuda during pregnancy; p1/HOMA-IR: the reciprocal of the homeostasis model assessment of insulin resistance during pregnancy; dISSI-2: insulin secretion sensitivity index postpartum; dMatsuda: insulin sensitivity index of Matsuda postpartum; dInsulinogenic index/HOMA-IR is a measure for beta-cell function postpartum; d1/HOMA-IR: the reciprocal of the homeostasis model assessment of insulin resistance postpartum; the $P$ values for the measurements during pregnancy are adjusted for age, BMI, ethnic background, multiparity, and corticoid treatment; the $P$ values for the measurements postpartum are adjusted for age, BMI, ethnic background, breastfeeding, and the progestin-only oral contraceptive. 
TABLE 4: Comparison of characteristics between women with an impaired fasting glucose (IFG) and women with an impaired glucose tolerance (IGT) postpartum.

\begin{tabular}{|c|c|c|c|}
\hline & IFG $N=14(21.2 \%)$ & IGT $N=44(66.7 \%)$ & $P$ value \\
\hline Age mean years & $31.4 \pm 4.4$ & $33.1 \pm 4.6$ & 0.244 \\
\hline $\mathrm{BMI} \mathrm{Kg} / \mathrm{m}^{2}$ at first prenatal visit (median) & $29.8(26.5-34.7)$ & $25.4(22.4-28.9)$ & 0.012 \\
\hline$\%$ overweight at first prenatal visit & 35.7 & 45.2 & 0.073 \\
\hline$\%$ obese at first prenatal visit & 50 & 14.3 & 0.006 \\
\hline$\%$ excessive weight gain & 42.9 & 20.9 & 0.106 \\
\hline$\% \mathrm{BME}$ & 50.0 & 40.9 & 0.550 \\
\hline$\%$ first degree family member with T2DM & 21.4 & 13.6 & 0.769 \\
\hline$\%$ history of GDM & 35.7 & 9.1 & 0.047 \\
\hline$\%$ multiparous & 50.0 & 36.4 & 0.592 \\
\hline$\%$ breastfeeding & 71.4 & 75.0 & 0.225 \\
\hline$\%$ progestin-only oral contraceptive & 66.7 & 71.4 & 0.756 \\
\hline Result GCT mg/dL (median) & $164.0(155.0-166.0)$ & $170.0(152.5-193)$ & 0.206 \\
\hline Week at diagnosis of GDM (median) & $25.0(20.5-27)$ & $27.0(25.0-28.7)$ & 0.029 \\
\hline$\%$ fasting abnormal $100 \mathrm{~g}$ OGTT & 83.3 & 34.9 & 0.003 \\
\hline$\% \geq 4$ values abnormal $100 \mathrm{~g}$ OGTT & 41.7 & 14.0 & 0.034 \\
\hline Median fasting $100 \mathrm{~g}$ OGTT mg/dL & $99.5(96.2-121.0)$ & $89.0(84.0-101.0)$ & 0.022 \\
\hline Median 1 h 100 g OGTT mg/dL & $202.5(183-226.2)$ & $189.0(170.0-202.0)$ & 0.047 \\
\hline Median 2 h 100 g OGTT mg/dL & $187.5(157.2-228.5)$ & $175.0(162.0-196.0)$ & 0.554 \\
\hline Median 3 h 100 g OGTT mg/dL & $147.5(110.5-181.5)$ & $152.0(139.0-163.0)$ & 0.927 \\
\hline$\%$ corticoid treatment & 0 & $9.1(4)$ & 0.242 \\
\hline$\%$ insulin & 42.9 & 29.5 & 0.355 \\
\hline Weeks start insulin (median) & $24.0(20.7-28.2)$ & $30.0(27.5-32.0)$ & 0.017 \\
\hline$\%$ bolus-basal injections & 66.7 & 38.5 & 0.412 \\
\hline
\end{tabular}

8 Women (12.1\%) with the combination of IFG and IGT were excluded from these analyses. BME: ethnic minority backgrounds; T2DM: type 2 diabetes; GDM: gestational diabetes; GCT: glucose challenge test; OGTT: oral glucose tolerance test.

TABLE 5: Comparison of the beta-cell function and the insulin sensitivity between women with an impaired fasting glucose (IFG) and women with an impaired glucose tolerance (IGT) postpartum.

\begin{tabular}{lcccc}
\hline & IFG $N=14(21.2 \%)$ & IGT $N=44(66.7 \%)$ & $P$ value & Adjusted $P$ value \\
\hline pISSI-2 mean & $1.3 \pm 0.6$ & $1.5 \pm 0.4$ & 0.211 & 0.927 \\
pMatsuda (median) & $2.2(1.2-3.0)$ & $3.0(1.9-3.7)$ & 0.132 & 0.695 \\
p1/HOMA-IR (median) & $0.013(0.010-0.018)$ & $0.022(0.013-0.034)$ & 0.070 & 0.813 \\
dISSI-2 (median) & $1.4(1.2-2.2)$ & $1.7(1.4-1.9)$ & 0.221 & 0.629 \\
dInsulinogenic index/HOMA-IR (median) & $0.005(0.002-0.009)$ & $0.010(0.007-0.015)$ & $\mathbf{0 . 0 0 3}$ & 0.087 \\
dMatsuda (median) & $3.2(1.6-3.8)$ & $4.8(3.1-7.7)$ & $\mathbf{0 . 0 0 4}$ & 0.075 \\
d1/HOMA-IR (median) & $0.020(0.015-0.022)$ & $0.038(0.021-0.062)$ & $<\mathbf{0 . 0 0 0 1}$ & $\mathbf{0 . 0 1 6}$ \\
\hline
\end{tabular}

pISSI-2: insulin secretion sensitivity index during pregnancy; pMatsuda: insulin sensitivity index of Matsuda during pregnancy; p1/HOMA-IR: the reciprocal of the homeostasis model assessment of insulin resistance during pregnancy; dISSI-2: insulin secretion sensitivity index postpartum; dMatsuda: insulin sensitivity index of Matsuda postpartum; dInsulinogenic index/HOMA-IR is a measure for beta-cell function postpartum; d1/HOMA-IR: the reciprocal of the homeostasis model assessment of insulin resistance postpartum; the $P$ values for the measurements during pregnancy and postpartum are adjusted for BMI.

population $[31,32]$. This is probably due to the high mean age of our cohort and the short follow-up after the delivery.

We also show that women with glucose intolerance or diabetes postpartum have an impaired beta-cell function and lower insulin sensitivity, remaining significant after adjustment for age, BMI, ethnicity, breastfeeding, contraception, multiparity, and corticoid treatment. Our data therefore highlight that variations in underlying maternal insulin secretion and sensitivity together with the degree of metabolic stress posed by factors specific to the pregnancy, all contribute to variations in postpartum risk for glucose intolerance.

Our data also show that women with IFG have a more adverse risk profile compared to women with IGT. The lower insulin sensitivity and lower beta-cell function in women with IFG seems to be largely driven by a higher BMI. IFG and IGT clearly represent different underlying deteriorations in 
glucose metabolism. Previous investigations have proposed that subjects with isolated IFG suffer from impaired firstphase insulin secretion and increased hepatic insulin resistance [33]. It has also been shown that when measurements of beta-cell function were adjusted for severity of insulin resistance, subjects with IGT and combined IFG/IGT had a significantly greater reduction in insulin secretion than subjects with IFG [34]. This is confirmed by our data showing that after adjustment for the BMI at first prenatal visit, only 1 /HOMA-IR remained significant in subjects with IFG. In contrast, impaired muscle insulin sensitivity is rather reflected by elevated $2 \mathrm{~h}$ glucose levels resulting in IGT [33, 34].

In our study, one fifth of women did not attend the scheduled OGTT postpartum. These women have an adverse risk profile compared to women who attended the scheduled OGTT postpartum. A telephonic recall for a new appointment for the postpartum OGTT increased the screening uptake with $10 \%$ in our cohort but more efforts are clearly necessary. In routine clinical care, reported postpartum testing rates are even lower with only $30-50 \%$ of women with recent GDM who receive an OGTT within 6 months after the delivery [35-37]. Annual follow-up rates are often even lower [38]. This is a missed opportunity in a highrisk population to timely detect glucose intolerance and start lifestyle interventions to prevent or delay the development of glucose intolerance and diabetes [39]. Other systems to improve early postpartum diabetes screening among women with GDM such as an electronic system to trigger reminder calls or postpartum SMS reminders might be helpful tools $[40,41]$. In a Southern Italian cohort of women with GDM, verbal and written counseling on the follow-up significantly increased the adherence rate [42]. In this study, the most compliant ones were older women, women with a previous history of GDM, higher educational levels, overweight or obese women, and those with insulin treatment. This is in contrast with the results of our study showing that women who failed to attend the postpartum OGTT had more often a previous history of GDM. More efforts are therefore necessary to better inform and create a greater awareness among these women of their future risk for developing diabetes. To better organize the long term follow-up to timely screen for diabetes in women with a history of GDM, in our center women are also invited to register in the Flemish project "Zoet Zwanger" (Sweet Pregnancy). This project is an initiative of the Flemish Diabetes Association and supported by the Flemish government, whereby women receive yearly remainders to have the FPG checked by their general practitioner [43].

Strengths of the study are the detailed characterization of a relatively large cohort of women with recent GDM using a good database. Multiple measures of beta-cell function and insulin sensitivity were calculated and adjusted for confounders. A limit of the study is the retrospective nature of the analysis and the lack of longer term data postpartum on the risk for glucose intolerance.

In conclusion, we show that glucose intolerance (IFG, IGT, and diabetes) is frequent in early postpartum and these women have an impaired beta-cell function and lower insulin sensitivity. One fifth of women did not attend the scheduled OGTT postpartum and these women have an adverse risk profile compared to women who received the OGTT postpartum.

\section{Conflict of Interests}

The authors declare that there is no conflict of interests regarding the publication of this paper.

\section{Acknowledgments}

Katrien Benhalima is the recipient of a Clinical Doctoral Scholarship of "FWO Vlaanderen" and Chantal Mathieu and Roland Devlieger are the recipients of a "Fundamenteel Klinisch Navorserschap FWO Vlaanderen.”

\section{References}

[1] American Diabetes Association, "Diagnosis and classification of diabetes mellitus," Diabetes Care, vol. 32, supplement 1, pp. S62-S67, 2009.

[2] International Association of Diabetes and Pregnancy Study Groups Consensus Panel, "International association of diabetes and pregnancy study groups recommendations on the diagnostic and classification of hyperglycemia in pregnancy," Diabetes Care, vol. 33, no. 3, pp. 676-682, 2010.

[3] American Diabetes Association, "Standards of Medical Care in diabetes-2014," Diabetes Care, vol. 37, supplement 1, pp. S14S80, 2010.

[4] D. A. Sacks, D. R. Coustan, D. R. Hadden et al., "Frequency of gestational diabetes mellitus at collaborating centers based on IADPSG consensus panel-recommended criteria: the Hyperglycemia and Adverse Pregnancy Outcome (HAPO) study," Diabetes Care, vol. 35, no. 3, pp. 526-528, 2012.

[5] HAPO Study Cooperative Research Group, "Hyperglycemia and adverse pregnancy outcomes," The New England Journal of Medicine, vol. 358, no. 19, pp. 1991-2002, 2008.

[6] R. Claesson, A. Åberg, and K. Maršál, "Abnormal fetal growth is associated with gestational diabetes mellitus later in life: population-based register study," Acta Obstetricia et Gynecologica Scandinavica, vol. 86, no. 6, pp. 652-656, 2007.

[7] L. Bellamy, J. P. Casas, A. D. Hingorani, and D. Williams, “Type 2 diabetes mellitus after gestational diabetes: a systematic review and meta-analysis," The Lancet, vol. 373, no. 9677, pp. 1773-1779, 2009.

[8] R. Oza-Frank, "Postpartum diabetes testing among women with recent gestational diabetes mellitus: PRAMS 2009-2010," Maternal and Child Health Journal, vol. 18, no. 3, pp. 729-736, 2014.

[9] International Diabetes Federation, Diabetes Atlas, International Diabetes Federation, Brussels, Belgium, 4th edition, 2010, http://www.eatlas.idf.org/.

[10] 2012, http://statbel.fgov.be/nl/statistieken/cijfers/bevolking/structuur.

[11] K. Benhalima, P. Van Crombrugge, R. Devlieger et al., "Screening for pregestational and gestational diabetes in pregnancy: a survey of obstetrical centers in the northern part of Belgium," Diabetology \& Metabolic Syndrome, vol. 5, no. 1, article 66, 2013. 
[12] K. Benhalima, "The VDV-VVOG-Domus Medica consensus 2012 on screening for pregestational diabetes in pregnancy and screening for gestational diabetes," Proceedings of the Belgian Royal Academies of Medicine, vol. 2, no. 1, pp. 24-42, 2013.

[13] J.-F. Vanderijst, F. Debieve, F. Doucet et al., "Stratégie de dépistage et critères diagnostiques du diabète gestationnel. Propositions du GGOLFB," Revue Médicale de Liège, vol. 67, no. 4, pp. 179-185, 2012.

[14] B. E. Metzger, T. A. Buchanan, D. R. Coustan et al., "Summary and recommendations of the Fifth International WorkshopConference on Gestational Diabetes Mellitus," Diabetes Care, vol. 30, supplement 2, pp. S251-S260, 2007.

[15] K. Benhalima, P. Van Crombrugge, M. Hanssens, R. Devlieger, J. Verhaeghe, and C. Mathieu, "Gestational diabetes: overview of the new consensus screening strategy and diagnostic criteria.," Acta clinica Belgica, vol. 67, no. 4, pp. 255-261, 2012.

[16] K. Benhalima, M. Hanssens, R. Devlieger, J. Verhaeghe, and C. Mathieu, "Analysis of pregnancy outcomes using the new IADPSG recommendation compared with the carpenter and coustan criteria in an area with a low prevalence of gestational diabetes," International Journal of Endocrinology, vol. 2013, Article ID 248121, 6 pages, 2013.

[17] Institute of Medicine (US) and National Research Council (US) Committee to Reexamine IOM Pregnancy Weight Guidelines, Weight Gain During Pregnancy: Reexamining the Guidelines, National Academies Press, edited by K. M. Rasmussen, A. L. Yaktine. The National Academies Collection: Reports funded by National Institutes of Health, Washington, Wash, USA, 2009.

[18] M. Matsuda and R. A. DeFronzo, "Insulin sensitivity indices obtained from oral glucose tolerance testing: comparison with the euglycemic insulin clamp," Diabetes Care, vol. 22, no. 9, pp. 1462-1470, 1999.

[19] D. R. Matthews, J. P. Hosker, A. S. Rudenski, B. A. Naylor, D. F. Treacher, and R. C. Turner, "Homeostasis model assessment: insulin resistance and $\beta$-cell function from fasting plasma glucose and insulin concentrations in man," Diabetologia, vol. 28, no. 7, pp. 412-419, 1985.

[20] S. E. Kahn, "The relative contributions of insulin resistance and beta-cell dysfunction to the pathophysiology of type 2 diabetes," Diabetologia, vol. 46, no. 1, pp. 3-19, 2003.

[21] A. E. Kitabchi, M. Temprosa, W. C. Knowler et al., "Role of insulin secretion and sensitivity in the evolution of diabetes type 2 in the Diabetes Prevention Program: effects of lifestyle intervention and metformin," Diabetes, vol. 54, no. 8, pp. 24042414, 2005.

[22] J. P. Kirwan, L. Huston-Presley, S. C. Kalhan, and P. M. Catalano, "Clinically useful estimates of insulin sensitivity during pregnancy: validation studies in women with normal glucose tolerance and gestational diabetes mellitus," Diabetes Care, vol. 24, no. 9, pp. 1602-1607, 2001.

[23] R. Retnakaran, Y. Qi, M. I. Goran, and J. K. Hamilton, "Evaluation of proposed oral disposition index measures in relation to the actual disposition index," Diabetic Medicine, vol. 26, no. 12, pp. 1198-1203, 2009.

[24] E. Noctor, C. Crowe, L. A. Carmody et al., "ATLANTIC DIP: simplifying the follow-up of women with previous gestational diabetes," European Journal of Endocrinology, vol. 169, no. 5, pp. 681-687, 2013.

[25] M. J. Picón, M. Murri, A. Muñoz, J. C. Fernández-García, R. Gomez-Huelgas, and F. J. Tinahones, "Hemoglobin A 1c versus oral glucose tolerance test in postpartum diabetes screening," Diabetes Care, vol. 35, no. 8, pp. 1648-1653, 2012.
[26] C. Kim, "Maternal outcomes and follow-up after gestational diabetes mellitus," Diabetic Medicine, vol. 31, no. 3, pp. 292-301, 2014.

[27] A. Barden, R. Singh, B. Walters, M. Phillips, and L. J. Beilin, "A simple scoring method using cardiometabolic risk measurements in pregnancy to determine 10-year risk of type 2 diabetes in women with gestational diabetes," Nutrition and Diabetes, vol. 3, p. e72, 2013.

[28] S. H. Kwak, S. H. Choi, H. S. Jung et al., "Clinical and genetic risk factors for type 2 diabetes at early or late post partum after gestational diabetes mellitus," Journal of Clinical Endocrinology and Metabolism, vol. 98, no. 4, pp. E744-E752, 2013.

[29] M. W. O’Reilly, G. Avalos, M. C. Dennedy, E. P. O’Sullivan, and F. Dunne, "Atlantic DIP: high prevalence of abnormal glucose tolerance post partum is reduced by breast-feeding in women with prior gestational diabetes mellitus," European Journal of Endocrinology, vol. 165, no. 6, pp. 953-959, 2011.

[30] E. P. Gunderson, M. M. Hedderson, V. Chiang et al., "Lactation intensity and postpartum maternal glucose tolerance and insulin resistance in women with recent GDM: the SWIFT cohort," Diabetes Care, vol. 35, no. 1, pp. 50-56, 2012.

[31] A. Malinowska-Polubiec, J. Sienko, Z. Lewandowski, K. Czajkowski, and R. Smoalrczyk, "Risk factors of abnormal carbohydrate metabolism after pregnancy complicated by gestational diabetes mellitus," Gynecological Endocrinology, vol. 25, no. 5, pp. 360-364, 2012.

[32] C. S. Göbl, L. Bozkurt, T. Prikoszovich, C. Winzer, G. Pacini, and A. Kautzky-Willer, "Early possible risk factors for overt diabetes after gestational diabetes mellitus," Obstetrics and Gynecology, vol. 118, no. 1, pp. 71-78, 2011.

[33] C. S. Göbl, L. Bozkurt, T. Prikoszovich, A. Tura, G. Pacini, and A. Kautzky-Willer, "Estimating the risk after gestational diabetes mellitus: can we improve the information from the postpartum OGTT?" American Journal of Physiology: Endocrinology and Metabolism, vol. 304, no. 5, pp. E524-E530, 2013.

[34] M. A. Abdul-Ghani, C. P. Jenkinson, D. K. Richardson, D. Tripathy, and R. A. DeFronzo, "Insulin secretion and action in subjects with impaired fasting glucose and impaired glucose tolerance: results from the veterans administration genetic epidemiology study," Diabetes, vol. 55, no. 5, pp. 1430-1435, 2006.

[35] B. R. Shah, L. L. Lipscombe, D. S. Feig, and J. M. Lowe, "Missed opportunities for type 2 diabetes testing following gestational diabetes: a population-based cohort study," BJOG: An International Journal of Obstetrics and Gynaecology, vol. 118, no. 12, pp. 1484-1490, 2011.

[36] J. Y. Ko, P. M. Dietz, E. J. Conrey et al., "Gestational diabetes mellitus and postpartum care practices of nurse-midwives," Journal of Midwifery and Women's Health, vol. 58, no. 1, pp. 3340, 2013.

[37] H. Bihan, E. Cosson, C. Khiter et al., "Factors associated with screening for glucose abnormalities after gestational diabetes mellitus: baseline cohort of the interventional IMPACT study," Diabetes \& Metabolism, vol. 40, no. 2, pp. 151-157, 2014.

[38] A. McGovern, L. Butler, S. Jones et al., "Diabetes screening after gestational diabetes in England," British Journal of General Practice, vol. 64, no. 618, pp. e17-e23, 2014.

[39] S. G. Gabbe, M. B. Landon, E. Warren-Boulton, and J. Fradkin, "Promoting health after gestational diabetes: a national diabetes education program call to action," Obstetrics and Gynecology, vol. 119, no. 1, pp. 171-176, 2012. 
[40] K. K. Vesco, P. M. Dietz, J. Bulkley et al., "A system-based intervention to improve postpartum diabetes screening among women with gestational diabetes," American Journal of Obstetrics and Gynecology, vol. 207, no. 4, pp. 283.el-283.e6, 2012.

[41] E. Heatley, P. Middleton, W. Hague, and C. Crowther, "The DIAMIND study: postpartum SMS reminders to women who have had gestational diabetes mellitus to test for type 2 diabetes: a randomised controlled trial-study protocol," BMC Pregnancy and Childbirth, vol. 13, article 92, 2013.

[42] C. Capula, E. Chiefari, A. Vero et al., "Predictors of postpartum glucose tolerance testing in Italian women with gestational diabetes mellitus," ISRN Endocrinology, vol. 2013, Article ID 182505, 6 pages, 2013.

[43] S. Verstraete and F. Muylle, "VDV-VVOG project Zoet Zwanger: klaar voor de tweede fase," Gunaikeia, vol. 18, no. 3, pp. 18-22, 2013. 


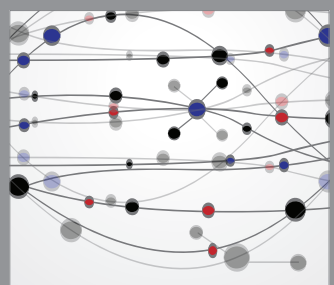

The Scientific World Journal
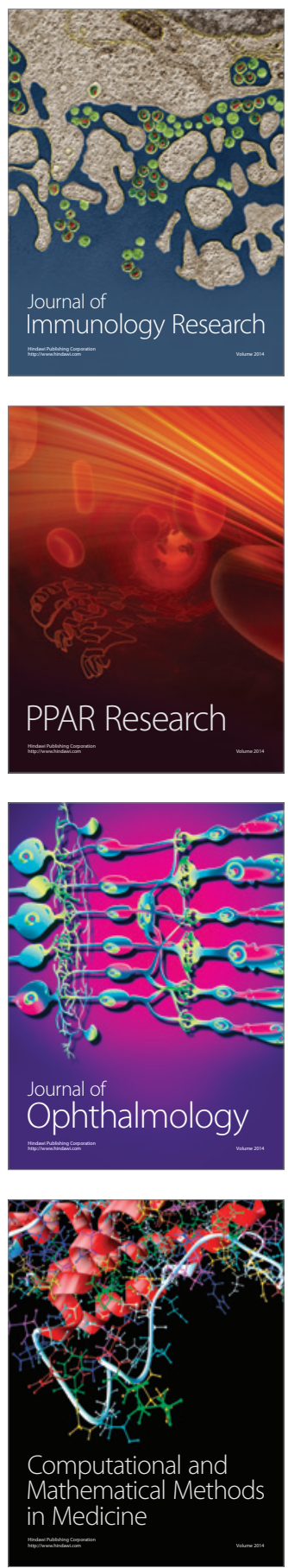

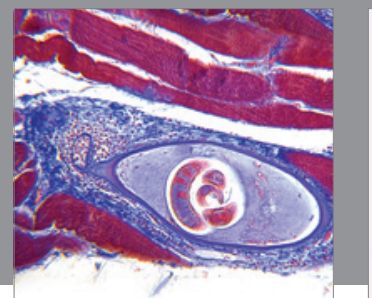

Gastroenterology

Research and Practice
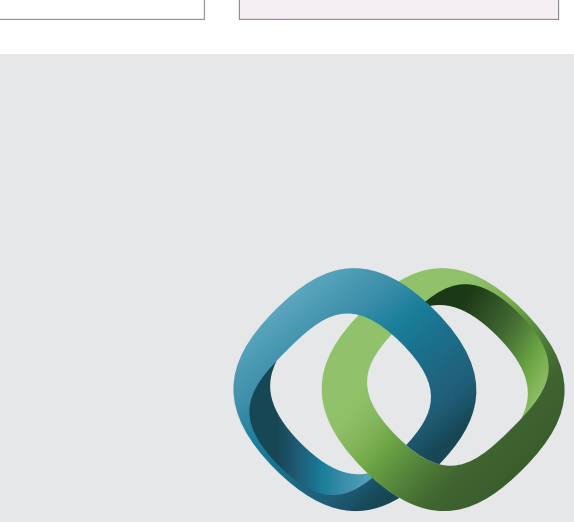

\section{Hindawi}

Submit your manuscripts at

http://www.hindawi.com
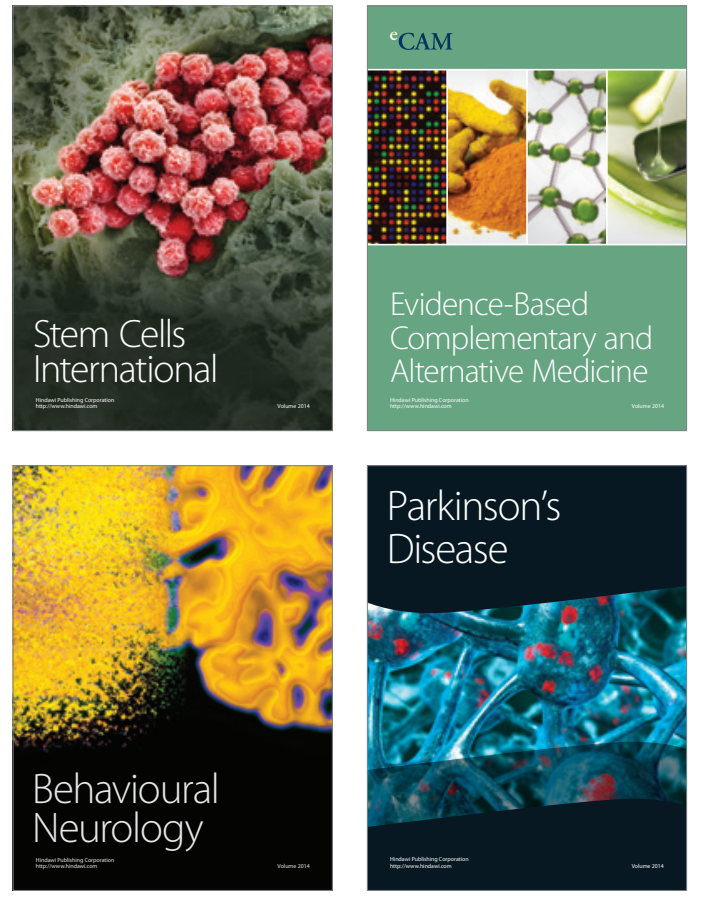
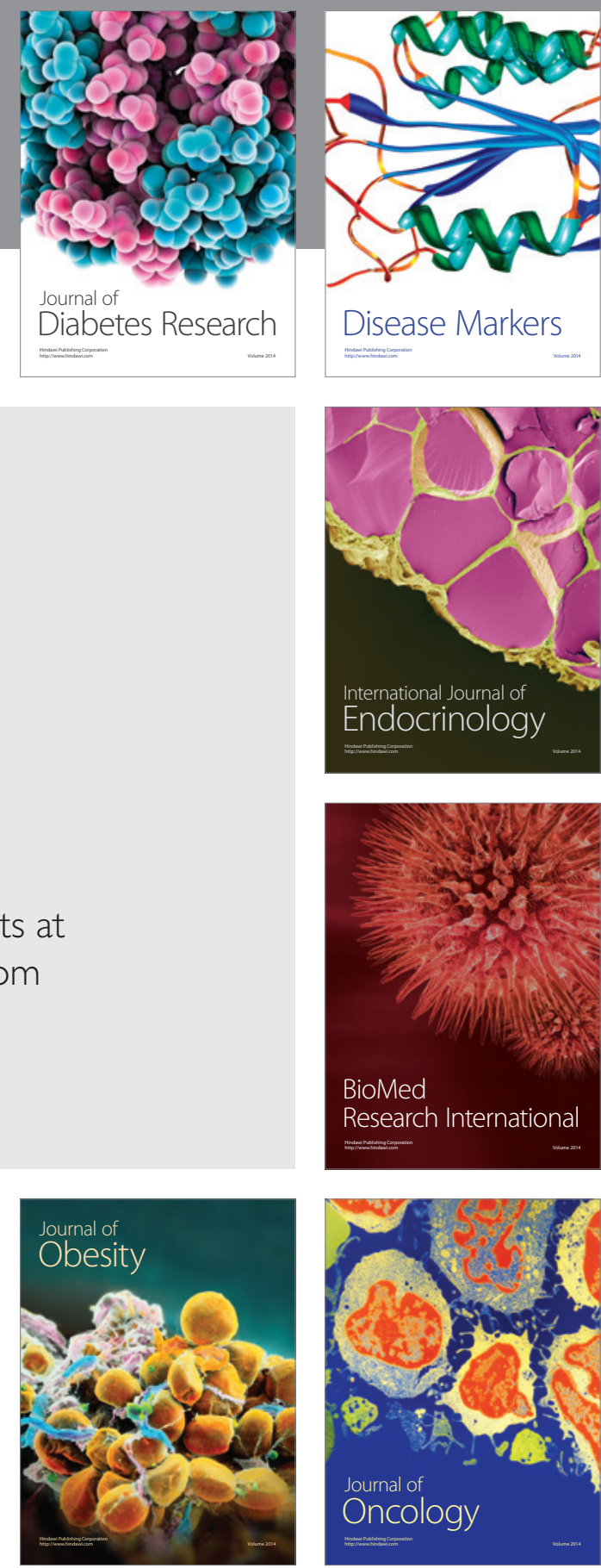

Disease Markers
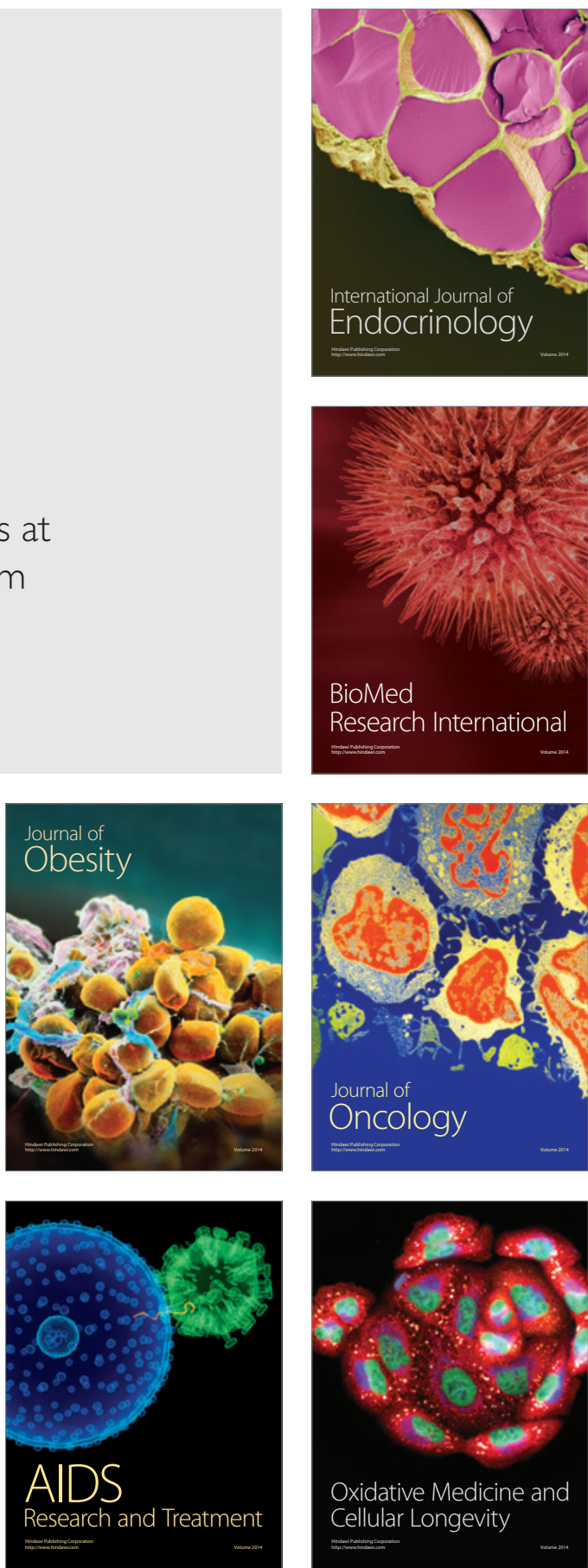